\title{
Restoring drinking water acceptance following a waterborne disease outbreak: the role of trust, risk perception, and communication
}

\author{
Boyka Bratanova1', Greg Morrison², Chris Fife-Schaw1, Jonathan Chenoweth', Mikael Mangold² \\ ${ }^{1}$ University of Surrey \\ ${ }^{2}$ Chalmers University of Technology
}

\begin{abstract}
Correspondence concerning this article should be addressed to Boyka Bratanova, University of Surrey, Guildford, Surrey GU2 7XH, UK. E-mail: b.bratanova@surrey.ac.uk
\end{abstract}

This research was carried out as part of Work Area 6 of the TECHNEAU project, an integrated project funded under FP6 of the European Commission, Grant No. 018320.

doi: 10.1111/jasp.12113

\begin{abstract}
Although research shows that acceptance, trust, and risk perception are often related, little is known about the underlying patterns of causality among the three constructs. In the context of a waterborne disease outbreak, we explored via zeroorder/partial correlation analysis whether acceptance predicts both trust and risk perception (associationist model), or whether trust influences risk perception and acceptance (causal chain model). The results supported the causal chain model suggesting a causal role for trust. A subsequent path analysis confirmed that the effect of trust on acceptance is fully mediated by risk perception. It also revealed that trust is positively predicted by prior institutional trust and communication with the public. Implications of the findings for response strategies to contamination events are discussed.
\end{abstract}

Trust plays an important role in allowing people to tolerate the growing uncertainty resulting from increasing technological and environmental complexity. The past two decades have uncovered a critical role of trust in relation to public perception of environmental and technological hazards. Accordingly, trust is now a central concept in this literature. Considerable attention has been devoted to examining the relationship between trust, risk perception, and acceptance giving rise to a wealth of theoretical developments and the accumulation of new empirical evidence (e.g., Breakwell, 2007; Cvetkovich \& Löfstedt, 1999; Renn, 2008; Siegrist, Earle, \& Gutscher, 2003). It is now well established that trust, risk perception, and acceptance are often closely related (Eiser, Miles, \& Frewer, 2002; Poortinga \& Pidgeon, 2005). However, it is far from clear what the patterns of causality among these factors are. On the one hand, considerable evidence suggests that trust in regulatory institutions plays an important role in shaping the public's estimation of risk related to the introduction of potentially hazardous products, technologies, or activities (e.g., Bord \& O'Connor, 1992; Cvetkovich \& Löfstedt, 1999; Dunlap, Kraft, \& Rosa, 1993; Frewer, 1999; Kasperson, Kasperson, Pidgeon, \& Slovic, 2003; Siegrist \& Cvetkovich, 2000; Slovic, 1993, 1997). On the other hand, a growing body of research demonstrates that judgments of acceptability based on prior attitudes toward hazards define trust in the respective institution and the perception of risk associated with the technology or activity (e.g., Dunlap et al., 1993; Eiser, Spears, \& Webley, 1989; Frewer, Howard, \& Shepherd, 1998).

Despite the apparent divergence of the existing findings, systematic examination of the causal relations between trust, risk perception, and acceptance has received relatively little attention (see Eiser et al., 2002; Poortinga \& Pidgeon, 2005). Although more research is needed to make conclusive assertions, it seems that there might be different mechanisms at work in different substantive domains. For instance, prior attitudes and acceptability appear to be leading factors in the domain of food technologies (e.g., genetically modified [GM] crops). Conversely, trust in the regulatory institutions has precedence in issues such as water saving (e.g., Jorgensen, Graymore, \& O'Toole, 2009). The clarification of the relationship between these factors in the previously unexamined context of a contamination event would thus represent an important theoretical advance.

The relationship between these factors is also of considerable practical utility. To date, little research has examined how trust, risk perception, and acceptability are linked in the domain of safe water supplies (for notable exceptions, see Hurlimann, Hemphill, McKay, \& Geursen, 2008; Po et al., 2005). One serious concern in the context of water 
supplies is waterborne disease outbreaks. Such outbreaks are likely to increase perceived risk, decrease acceptance, and undermine trust. Thus, after disease outbreaks both private companies and public institutions engaged in water supply are faced with the task of reestablishing acceptance and trust while reducing perceived risk. This research will help identify what practices and measures may be most effective to minimize the negative social consequences due to waterborne contamination, both during and after an outbreak. If preexisting trust in the institutions regulating water supply has a defining role in how people perceive risk, dissemination of post-outbreak information aimed at reassurance may serve to lower perceived risks and to restore consumers' acceptance of drinking water within a relatively short period. If prior attitudes (assumed to be negative in the context of a contamination event) drive the evaluation of all aspects of the situation, including trust and risk perception, then authorities may need to adopt a rather different approach in attempting to restore consumers' satisfaction and the credibility of their institution (White \& Eiser, 2005; White, Pahl, Buehner, \& Haye, 2003). Examining the patterns of causality among trust, risk perception, and acceptance is therefore not only of theoretical, but also of practical importance. Based on the findings of this research, we discuss recommendations to water supply authorities with respect to the effectiveness of different strategies for handling waterborne contamination events.

To guide our research, we draw on two models proposed by Eiser et al. (2002) that capture the commonly identified causal relationship patterns among trust, risk perception, and acceptance. The account suggesting that trust influences risk perception, which in turn influences acceptance, is referred to as the causal chain model (Figure 1). This model stipulates an analytic approach to the formation of risk-related attitudes. It proposes that people engage in a rational and deliberate processing of information about a potentially hazardous policy or activity (see also Slovic, Finucane, Peters, \& MacGregor, 2004). The risks and benefits associated with the hazards are carefully considered, as well as the positive or negative consequences of their implementation. Trust in the relevant institution has a critical role throughout the evaluation process as the information provided by this institution may directly influence attitude formation. Arguably, trust in the source of information does not necessarily result in trust in the specific information being released: Institutional trust usually stems from a general evaluation of an institution's

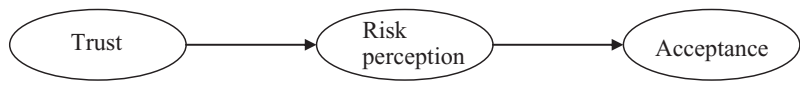

Figure 1 The causal chain model. values and performance over time, while trust in the message is specific to the issue under consideration (e.g., Miles \& Frewer, 2000). Nevertheless, there is ample evidence that individuals do tend to form their attitudes and plan their actions on the basis of information provided by those whom they regard as trustworthy (e.g., Echterhoff, Higgins, \& Levine, 2009; Hardin \& Higgins, 1996). The causal chain model would thus predict that if a trusted institution releases information designed to be reassuring, it should reduce the levels of risk perceived by the public and increase the public's acceptance of the technology or activity. In the context of a waterborne disease outbreak, it is more appropriate to focus on preserving or restoring public's acceptance of the water being supplied, as no new technology or product is being introduced.

The alternative account, termed the associationist model (Figure 2), suggests that judgment of acceptability may precede and in fact determine the levels of trust and perceptions of risk associated with the potentially hazardous policy (Eiser et al., 2002). In other words, in this model both trust and risk perceptions are outcomes of the more general acceptance of a particular activity or technology.

In the associationist model, judgments of acceptance are based on prior attitudes toward the activities or technologies under consideration. The effects of prior attitudes are especially pronounced for issues subject to substantial societal controversy that may have caused attitude polarization and/or issues that tend to elicit affective responses (e.g., GM food; see Eiser et al., 2002; Poortinga \& Pidgeon, 2005). The role of affect deserves special attention because affective responses may occur automatically and precede extensive cognitive processing of relevant information (Finucane, Alhakami, Slovic, \& Johnson, 2000). This initial affective reaction toward a topic may influence subsequent judgments and information processing (Zajonc, 1980), which has important implications for understanding how lay perceptions of hazards are formed (Alhakami \& Slovic, 1994; Finucane et al., 2000; Loewenstein, Weber, Hsee, \& Welch, 2001; Rundmo, 2002; Slovic et al., 2004). To summarize, the associationist approach proposes that people's initial (affective) response to a potential hazard can trigger congruent risk perceptions and influence trust in the respective institution.

Eiser et al. (2002) and Poortinga and Pidgeon (2005) put the causal chain and the associationist models to the test in the domain of food technology. Using a partial correlation

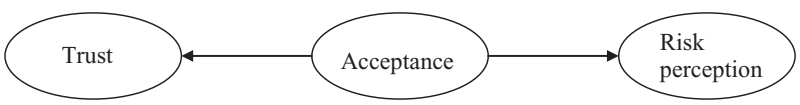

Figure 2 The associationist model. 
approach, these authors reasoned that if the causal chain model applies, trust would predict risk perception which in turn would predict acceptance of the new technology. That is, to support this model risk, perception should mediate the relationship between trust and acceptance. If the associationist model provides a better account for the relationship among the three factors, the initial correlation between trust and risk perception should become nonsignificant after controlling for acceptance. At the same time, the correlation between trust and acceptance should remain relatively unchanged after controlling for the effect of risk. In line with previous research on food technology (Frewer et al., 1998), the findings from these studies provided stronger support for the associationist model, although partial support for the causal chain was obtained as well (Eiser et al., 2002; Poortinga \& Pidgeon, 2005).

As mentioned earlier, there is relatively little research on the relationship among trust, risk perception, and acceptance in the context of water. A notable exception is the study by Po et al. (2005) in the domain of water reuse. They conducted an investigation to identify the different factors that might influence people's decision to accept (i.e., drink) partially recycled water. These authors employed Ajzen's (1985) theory of planned behavior to investigate communities' responses to an indirect potable reuse scheme in Perth, Australia-an area facing long-term water shortages. In response to these shortages, the managed aquifer recharge reuse scheme had been proposed, which would involve the introduction of treated wastewater into the local aquifer. On the basis of their model, Po et al. found that respondents' stated intention to drink water from the scheme could be predicted primarily by their attitudes. Thus, although they did not directly test the causal chain and the associationist models, their analysis pointed to a causal role for emotions (measured as disgust) in determining attitudes and thence intentions, and suggested at least a bidirectional relationship between emotions and trust. Their model is thus partially consistent with the associationist account of acceptance but also contains elements of the causal chain model.

In this paper, we examine what causal patterns exist among trust, risk perception, and acceptance in the context of a waterborne disease outbreak. In particular, we examine whether the causal chain or the associationist model is more appropriate in predicting people's response to a water contamination event. The contamination event in Lilla Edet, Sweden, in September 2008 provided a case study to test the applicability of the two models. A secondary aim of the paper is to examine which factors influence trust if the causal chain model applies, or alternatively, which factors influence acceptance if the associationist model applies. We now turn to describing the details of the water contamination event that took place in Lilla Edet in order to provide the context for this study.

\section{Background to the contamination event in Lilla Edet}

The municipality of Lilla Edet has typically enjoyed a reliable, high-quality water supply. In 2005, Lilla Edet received a prize for tastiest water in Sweden by the Swedish Water and Wastewater Association. The award was a source of considerable local pride and there had been no waterborne outbreaks in recent memory. In light of this, it is believed that Lilla Edet inhabitants were highly satisfied with the water supply in the municipality and had high levels of trust in the authorities involved in the water service provision.

In September 2008, at least 2,000 people in a population of approximately 9,000 people fell ill in a calicivirus outbreak. The authorities acted swiftly. The senior environmental officer in Lilla Edet made a public announcement that the tap water was not to be drunk before boiling (as a safety precaution) only 2 hours after the first alarm about people falling ill (Ekvall, 2010). In that same day, the contamination protection unit (Smittskyddsenheten [SME]), the municipality, the National Food Administration (Livsmedelsverket), the county authority (Länsstyrelsen), the infectious disease institute (Smittskyddsinstitutet), the virological laboratory at the Sahlgrenska University Hospital, and the local health center (Vardcentralen) formed a crisis group under the auspices of the National Water Catastrophe Group (Nationella vattenkatastrofgruppen). Regular telephone meetings were held, and clear directions were given to the inhabitants (Ekvall, 2010).

During the outbreak, the dosage of chlorine intended to disinfect the water was increased and measurable water quality indicators yielded acceptable results (Heinicke et al., 2010). However, according to Ekvall (2010), it was also clear that it was the water that had caused the outbreak. The employees at the waterworks felt unfairly blamed indirectly when the water was said to be the carrier of pathogens. In January 2009, they contested the claim that the water caused the outbreak in a local newspaper. A senior environmental officer in Lilla Edet municipality stated that the investigation of the cause of the incident performed by SME was inconclusive. These conflicts are likely to have resulted in uncertainties among the public in Lilla Edet. The two main sources of uncertainty were with regard to: (a) the actual cause of the outbreak and (b) what actions had been taken to prevent a similar outbreak.

\section{Aims and hypotheses}

The primary aim of the article is to explore the pattern of causality among trust, perception of risk associated with water use, and the acceptance of the drinking water quality and service after contamination. As mentioned previously, the applicability of two alternative models is tested (causal chain 
and associationist models; Eiser et al., 2002). The secondary aim is to examine which factors influence trust if the causal chain model applies, or alternatively, which factors influence acceptance if the associationist model applies. Identifying the predictors of trust or acceptance, respectively, may inform policy makers on what strategies to adopt in their efforts to rectify the negative social consequences of a contamination event.

In line with the predictions of the causal chain model, Cvetkovich and colleagues have argued that preexisting levels of trust critically determine the impact negative events may have (Cvetkovich, Siegrist, Murray, \& Tragesser, 2002). Although formal measures are not available, given the water quality prize and anecdotal evidence from residents, we believe it is reasonable to assume that the Lilla Edet public held the municipal authorities in high regard before the contamination event. It is also worth noting that relative to other contamination events, the communication with the public was clear and timely (Kelay \& Fife-Schaw, 2011). Swift release of good quality information may contribute to preserving the high level of preexisting trust (for a similar argument, see Eiser et al., 2002). Furthermore, although official reports claimed that it was the water that caused the calicivirus outbreak, this conclusion had not been universally accepted and the public had not received definitive information about what or who caused the disease outbreak. Perceptions that the outbreak was caused by institutional incompetence may undermine trust and increase the perception of risk, partly because it signals an increased likelihood of another outbreak (e.g., Burns et al., 1993). Although there was uncertainty as to what measures were taken to prevent future outbreaks, ambiguity about who or what was responsible for the outbreak may act as a buffer to the presumably high levels of preexisting trust in the water supply authorities. Taken together, these factors would suggest that if the causal chain model applies, the assumed high levels of trust in the institutions involved in water supply would lead to lower perception of risk associated with post-contamination water use, and high levels of acceptance of the drinking water and the supply service.

However, there are similarly good reasons why the associationist model could provide a better account for a contamination event like the one in Lilla Edet. To start with, the incident resulted in sickness, which, although not life threatening, involved considerable discomfort of several days duration. More than $20 \%$ of the population fell ill. It is probably safe to assume that any prior attitudes toward sickness due to contamination would be negative. It is also highly likely that a disease outbreak on such a scale would elicit negative affective reaction. Research on classical conditioning has demonstrated that poisoning resulting from food or liquid consumption elicits strong aversive responses (e.g., Bernstein, 1999). Hence, if the associationist model applies, one may expect low levels of acceptance of the drinking water, result- ing in high perception of risk and in low trust in the water supply authorities. Since this approach relies on affective reactions and attitudes toward the hazard, ambiguity surrounding the cause of the outbreak should not influence risk perception or acceptance. The predictions derived from the two models are tested against the obtained variability of the three constructs: trust, risk perception, and acceptance.

\section{Analytic approach}

An approach comparing the zero-order and partial correlations among the constructs was employed to test the hypotheses derived from the causal chain and the associationist models (for similar approach, see Eiser et al., 2002; Poortinga \& Pidgeon, 2005). The causal chain model is supported if an initial zero-order correlation between trust and acceptance is significantly reduced after controlling for risk perception. At the same time, the partial correlations between trust and risk perception (while controlling for acceptance) and between risk perception and acceptance (while controlling for trust) should remain significant. The associationist approach is supported if controlling for acceptance substantially reduces the initial zero-order correlation between trust and risk perception. The partial correlations between acceptance and trust (while controlling for risk perception) and between acceptance and risk perception (while controlling for trust) should remain relatively unchanged compared to their zeroorder counterparts.

To test the associationist and the causal chain models and to be consistent with previous approaches to this problem, we used measures of trust, acceptance, and risk perception obtained in the second wave of the survey. As we have no $a$ priori prediction about which model would apply in the case of a water contamination event, we could not impose a temporal order and use a time-lagging strategy (i.e., using measures of factors in Wave 1 to predict a factor measured in Wave 2 ) to test for the causal role of trust or acceptance. However, we used a time-lagged strategy in a follow-up path analysis to examine which factors predict the causal root-trust or acceptance-once it had been established.

\section{Method}

\section{Participants and procedure}

Two questionnaire surveys were sent to the same 1,000 inhabitants in Lilla Edet. The 1,000 adult Lilla Edet inhabitants were randomly selected using the Swedish National Address Register (Statens Personadressregister). From the randomly selected 1,000 people who were sent questionnaires by mail in each wave of the survey, about 620 were provided with water from Lilla Edet, with the remaining depending upon private water supply sources such as wells. The response rate from 
Wave 1 was 401 of whom 268 were supplied with municipal water. In Wave 2, the response rate was 347 of whom 205 were supplied with municipal water. Of the total sample of 506 respondents $\left(M_{\text {age }}=51.14, S D=14.63\right)$ who took part in the survey, 242 replied in both Wave 1 and Wave 2, and of these respondents 158 had municipal water supplies.

The first questionnaire was sent out on January 2, 2009. One reminder containing a copy of the questionnaire was sent out 1.5 months after the first dispatch. The second wave was sent out in September 2009. Two reminders containing a copy of the questionnaire were sent out in October and November 2009. Items from both Waves 1 and 2 are used for the purposes of this study.

\section{Measures}

The measures used in the analyses are presented below. If not stated otherwise, a 9-point Likert-type scale ( $1=$ Do not agree at all to $9=$ Totally agree) was used to assess the extent to which respondents agreed with statements designed to measure the respective constructs.

\section{Trust in the municipal authorities (Wave 1)}

The trust scale used in Wave 1 of the survey consisted of six items ("The water plant uses first class, modern techniques, for the purification of the water," "The people working at the waterworks have the consumers' interests at heart," "The people working at the waterworks have high competence to produce tap water," "The politicians in the municipality have enough knowledge about the water distribution issue to make good decisions on the subject," "I felt that the authorities had the situation under control and knew what they were doing," and "I trust that the authorities in the future will provide me with good information about possible problems with the drinking water"). As the scale showed a good internal consistency (Cronbach's $\alpha=.85$ ), all items were retained in the analysis and averaged to form a composite measure of trust.

It should be noted that in Lilla Edet the municipality runs the water supply system and employs the water workers. Thus, as far as water supply is concerned, municipality politicians and water plant workers are likely to be perceived by the public as a unified authority that is responsible for the provision of safe drinking water. ${ }^{1}$

\footnotetext{
${ }^{1}$ The following two items were used to check the assumption that the municipality politicians and the water plant workers are perceived as equally responsible for the water supply: "It is the municipality politicians' responsibility to provide tap water of good quality" and "It is the management at the water work's responsibility to provide tap water of good quality." The high ratings on both measures $(M=7.85, S D=1.81$ for municipality politicians; $M=8.07$, $S D=1.68$ for waterworks management) confirmed that both politicians at the municipality and the water plant workers are held responsible for the safety of water to a similar extent.
}

\section{Trust in the municipal authorities (Wave 2)}

In Wave 2, the same six items were used to measure trust in the authorities. As in Wave 1, the scale showed good reliability (Cronbach's $\alpha=.90$ ).

\section{Acceptance (Wave 2)}

Three items were used to measure inhabitants' acceptance of the municipal water supply. In one of the items, the respondents were asked to rate the tap water taste on a 9-point scale $(1=$ Not good at all, $9=$ Excellent $)$. Also on a 9-point scale $(1=$ Not at all, $9=$ Very much $)$, the inhabitants were asked to indicate the extent to which they would have preferred to have their own well if they could, and the extent to which they appreciated being part of the municipal water system. The three items formed a scale with acceptable reliability (Cronbach's $\alpha=.71$ ) and were averaged in a composite measure of acceptance.

\section{Risk perception (Wave 2)}

A single item was used to measure the perceived risk associated with drinking municipal water ("How safe do you feel when you drink the water?"). Respondents were asked to indicate their answer on a 9-point scale ( $1=$ Not safe at all, $9=$ Absolutely safe).

\section{Municipal authorities blamed (Wave 1)}

The attribution of blame was measured by a single question, "Whose fault do you think it was that the incident in Lilla Edet occurred?" with eight closed options and an open option given, allowing multiple answers for the response. A binary index was created for the analysis which indicated whether or not the respondent had indicated that any of the municipality's agents, either the politicians, the management, or the employees of the waterworks, were responsible and so the index differentiated between blame placed on the authorities involved in the water supply or on other causes.

\section{Upstream sewage discharge blamed (Wave 1)}

The same question, "Whose fault do you think it was that the incident in Lilla Edet occurred?" was used to create a binary index of whether respondents thought that the municipalities upstream from Lilla Edet discharged sewage into the Lilla Edet water supply, causing the outbreak. At the time of writing, this was believed to be the primary cause of the event, and thus in some senses is the correct attribution of blame.

\section{Message quality (Wave 1)}

To assess the quality of the information released, the respondents were asked to rate to what extent they believed it was good, understandable, correct, biased (reversely scored), 
Table 1 Descriptive Statistics of Key Continuous Variables

\begin{tabular}{llll}
\hline & $M$ & SD & $n$ \\
\hline Trust (Wave 1) & 5.20 & 1.71 & 358 \\
Trust (Wave 2) & 5.26 & 1.73 & 321 \\
Acceptance (Wave 2) & 5.92 & 2.26 & 214 \\
Risk (safety; Wave 2) & 6.76 & 2.26 & 215 \\
Message quality (Wave 1) & 5.29 & 1.50 & 319 \\
\hline
\end{tabular}

Note. Ratings on all measures were made on a 9-point scale.

Numbers vary due to missing data.

frightening (reversely scored), sufficient, honest, and timely. The eight items formed a scale with good reliability (Cronbach's $\alpha=.86$ ).

\section{Experienced sickness (Wave 1)}

A binary indicator of experienced sickness was constructed using two items measuring whether the respondents or someone else in the respondents' household got sick with gastrointestinal symptoms during the incident. ${ }^{2}$

\section{Home municipal water user}

Respondents were asked to indicate whether they have municipal water in their home. ${ }^{3}$ It is worth noting, however, that not being a customer of the municipal water supply service does not preclude these inhabitants using the municipal water in other locations in Lilla Edet, for example, at work, at school, or at friends' houses. Therefore, their responses may still provide valid, albeit somewhat differently nuanced reports of the various aspects of the incident. This variable is therefore controlled for in the analysis.

\section{Results}

An examination of the mean ratings of acceptance of the drinking water and perceptions of the water safety indicate that the public retained fairly positive post-contamination views of the water quality (Table 1 ). The public's evaluation of the information released was also generally favorable (Table 1), confirming the experts' assessment of the communication process during the incident (Ekvall, 2010; see also Kelay \& Fife-Schaw, 2011). The mean ratings of trust in the municipal authorities were moderately positive in both waves of the survey (Table 1). To assess whether the contamination

${ }^{2}$ The official report on the Lilla Edet contamination event indicated that at least 2,000 people in a population of 9,000 have fallen sick due to the calicivirus outbreak. This officially estimated percentage of people falling sick $(22.2 \%)$ is comparable with the percentages obtained in the current survey: $24.1 \%$ of respondents indicated they had fallen sick, and $24.8 \%$ reported that someone else in their household had fallen sick.

${ }^{3}$ Some residents in outlying areas of the town have their own wells and are not directly connected to the municipal water supply.
Table 2 Breakdown of Binary-Coded Variables Measured at Wave 1 $(n=401)$

\begin{tabular}{lcl}
\hline & Frequency & Percentage \\
\hline Municipal authorities blamed & 80 & 20 \\
Upstream sewage discharge blamed & 133 & 33 \\
Experienced sickness & 140 & 35 \\
\hline
\end{tabular}

incident had any effects on trust levels over time, a pairedsamples $t$ test using the trust measures at Waves 1 and 2 was performed, revealing no significant difference, $t(207)=-.36$, $p=.206$. That is, the levels of trust remained largely unchanged between the 5th and the 13th month following the contamination incident. The number and percentage of respondents who indicated they or a member of their household got sick, attributed blame to the municipality authorities, and attributed blame to the upstream municipalities for sewage discharge are presented in Table 2.

To examine the causal pattern among trust, acceptance, and risk perception, the zero-order and partial correlations among the three variables were examined (Table 3). All measures included in this analysis come from the second wave of the survey. Consistent with the predictions of the causal chain model, the initial significant correlation between trust and acceptance was eliminated when controlling for risk perception. Both the partial correlations between trust and risk (while controlling for acceptance), and risk and acceptance (while controlling for trust) remained significant. These results suggest that the causal chain model provides a good explanatory account for our data. No clear support was obtained for the associationist model as controlling for acceptance only modestly weakened the correlation between trust and risk perception.

We sought to further extend the causal chain model by examining which factors influence trust. To do that, we designed a path model in which six variables measured at Wave 1 were included as predictors of trust at Wave 2. These were: trust at Wave 1, the perceived quality of the information provided at the time of the outbreak, whether blame was attributed to the municipal authorities, whether respondents believed the outbreak was caused by a sewage discharge, whether they or a family member had experienced sickness at the time of the incident, and whether they were customers of the municipal water supply. ${ }^{4}$ To put the predictions of the causal chain account to a more rigorous test mediation by risk

${ }^{4}$ The variable indicating whether the respondents were customers to the municipal water supply was extremely skewed as only five respondents indicated they had alternative water supply in the sample of 120 cases with complete data at both waves of the study. The lack of variability did not allow a reliable test of the effect of this variable to be carried out and it was excluded from the analysis. 
Table 3 Zero-Order and Partial Correlation between Trust, Perceived Risk, and Acceptance (All Measured in Wave 2)

\begin{tabular}{lllll}
\hline Relationship & Zero-order correlation & $n$ & Controlling for: & Partial correlation \\
\hline Trust $\times$ Risk & $.50 * *$ & 204 & Acceptance & $.35^{* *}$ \\
Risk $\times$ Acceptance & $.64 * *$ & 212 & Trust & $.56 * *$ \\
Trust $\times$ Acceptance & $.39 * *$ & 203 & Risk & .11 \\
\hline
\end{tabular}

Note. ${ }^{* *} p<.001$.

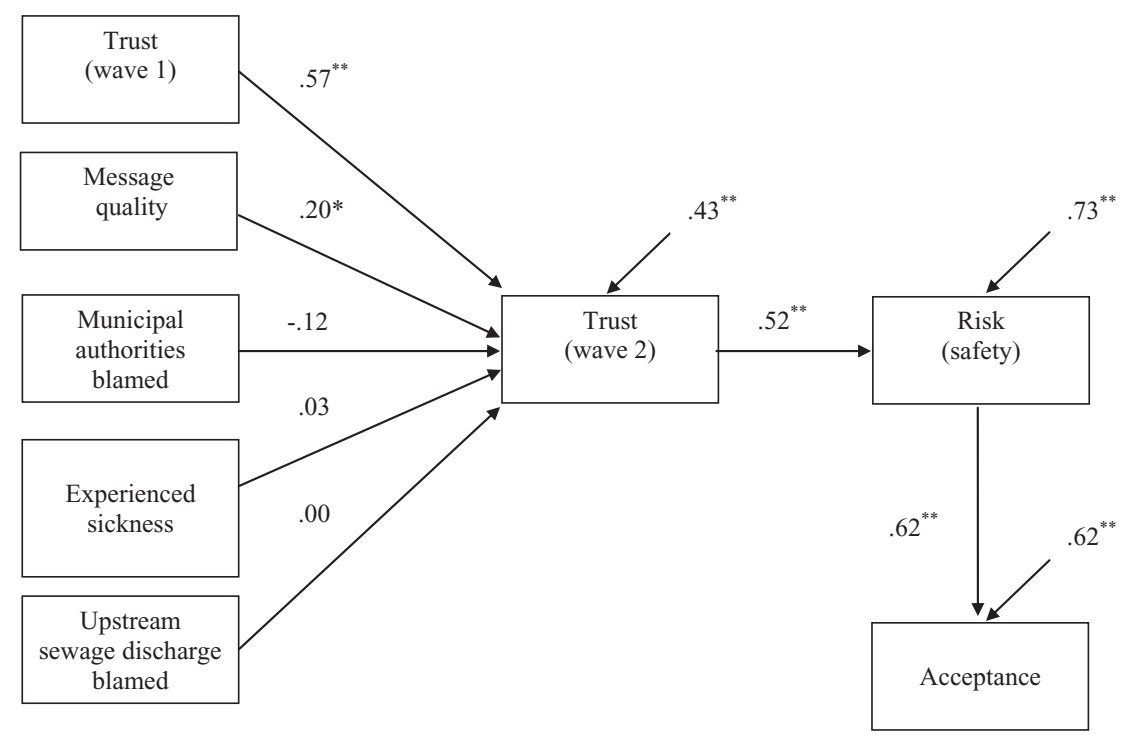

Figure 3 Path model of the relationships between predictors of trust (Wave 2), risk perception, and acceptance. Figures are standardized path coefficients $(n=120)$. For the sake of clarity, correlations between Wave 1 exogenous variables are not shown (see Table 4$) .{ }^{*} p<.05 .{ }^{* *} p<.001$.

perception of the effect of trust (Wave 2) on acceptance was also proposed in the path model.

The path model was tested using structural equation modeling ${ }^{5}$ on 120 cases for which complete data were available. The model had adequate fit indices, $\chi^{2}(11)=15.35, p=.17$, $\mathrm{NNFI}=.97, \mathrm{CFI}=.99, \mathrm{RMSEA}=.06$, and a specification search suggested no meaningful changes to the model could be made. This model is presented in Figure 3.

The path analysis revealed that risk perception fully mediated the effect of trust on acceptance. Respondents' prior level of trust in the municipal authorities (as measured in Wave 1) was a strong predictor of trust at Wave 2. Evaluation of the message quality was also a positive and significant predictor of trust at Wave 2. Together with the positive ratings of these key factors (Table 1), these results support the broader predictions of the causal chain model that reassuring

${ }^{5}$ The modeling was conducted on observed variables as the sample size was insufficient to allow estimation of all the parameters when using a latent variable approach. Covariances were modeled using maximum likelihood estimation. information released by trusted institutions has the capacity to mitigate risk perception and preserve acceptance.

The negative effect of blame laid on the municipal authorities did not reach standard levels of significance. However, it should be noted that blaming the authorities was negatively correlated with trust at Wave 1 and with message quality $(r s=-.46$ and -.46 , Table 4$)$. The measures of message quality and trust at both waves were also highly correlated ( $r s=.57$ and .57$)$, as were the measures of trust in both waves $(r=.73)$. Thus, rather than indicating a lack of substantive effect, the weak and nonsignificant path from blame to trust at Wave 2 appears to be due to the high degree of shared variance between blame and trust at Wave 1, and blame and message quality. When blame was included as a predictor of trust at Wave 2 along with trust at Wave 1 and message quality, the shared variance appears to be accounted for by the effect of the latter two variables. Similarly, although the experience of sickness had no direct influence on trust at Wave 2 (Figure 3), it was related to evaluation of the message quality $(r=-.29$, Table 4$)$ and levels of trust at Wave $1(r=-.35)$. It seems likely that experiencing sickness and attributing blame 
Table 4 Descriptive Statistics and Correlations among the Variables Included in the Path Model

\begin{tabular}{|c|c|c|c|c|c|c|c|c|c|c|}
\hline & $M$ & $S D$ & $\%$ & 1 & 2 & 3 & 4 & 5 & 6 & 7 \\
\hline 1. Risk (safety) & 6.63 & 2.29 & & - & & & & & & \\
\hline 2. Acceptance & 6.32 & 1.86 & & .62 & - & & & & & \\
\hline 3. Trust (Wave 2) & 5.33 & 1.55 & & .52 & .42 & - & & & & \\
\hline 4. Trust (Wave 1) & 5.32 & 1.67 & & .41 & .39 & .73 & - & & & \\
\hline 5. Message quality & 5.36 & 1.70 & & .26 & .27 & .57 & .57 & - & & \\
\hline 6. Municipal authorities blamed & & & 25.8 & -.29 & -.20 & -.46 & -.46 & -.44 & - & \\
\hline 7. Experienced sickness & & & 42.5 & -.27 & -.13 & -.26 & -.35 & -.29 & .30 & - \\
\hline 8. Upstream sewage discharge blamed & & & 39.2 & -.15 & .00 & .05 & .06 & .05 & -.01 & .14 \\
\hline
\end{tabular}

Note. $n=120$. Correlations $>.18$ are statistically significant at $p<.05$.

to the municipal authorities during the event had immediate impacts on trust levels and perceptions of the information released, and these impacts have persisted over time.

Finally, respondents' belief that the outbreak was caused by sewage discharge had no effect on trust at Wave 2 (Figure 3 ). It was not associated with acceptance of the water either $(r=.00$, Table 4$)$, further confirming that direct affective responses toward the source of the contamination did not play a role in forming the public's perceptions of the event.

\section{Discussion}

The current research examined the pattern of causal relationships among trust, risk perception, and drinking water acceptance in a case of waterborne disease outbreak. Two alternative models were tested: the causal chain and the associationist models. By comparing the zero-order and the partial correlations among the constructs, trust in the water supply authorities was found to directly predict consumers' perception of risk associated with water use, which in turn predicted their acceptance of the water and the water supply service. The same pattern of results was obtained via path analysis, providing further support for the causal chain account. The associationist view was less consistent with the data. Contrary to that model, the correlation between trust and risk perception was only weakly reduced after controlling for the effect of acceptance. These results indicated that in the context of a waterborne disease outbreak, trust in the regulatory institutions, and not prior attitudes toward a contamination event, defines public's risk evaluation and acceptance of the post-incident water use and supply.

These findings differ from those obtained in previous research in related domains, such as the decision to accept partially recycled water for potable purposes (Po et al., 2005) and the introduction of new food technologies, such as GM food (Eiser et al., 2002; Poortinga \& Pidgeon, 2005). Water reuse and GM food were better explained by the associationist model. Po et al. found that emotional reaction, measured as disgust, had a determining effect on people's willingness to drink recycled water. Similarly, greater support was found for the causal role of prior attitudes toward various food technologies. The sporadic nature of the waterborne contamination event may be responsible for the different causal patterns: While issues of genetic modification and water reuse have been the subject of public discourse for some time, it is unlikely that negative contamination-related affects and attitudes have been salient before the event.

In the present study, the predictions of the causal chain model were supported not only with regard to the causal pattern between trust, risk perception, and acceptance, but also with regard to the role that prior trust and communication with the public play in establishing the links between the three constructs. The model stipulated that prior trust in the relevant institutions and information released by these institutions may critically influence the evaluation of the risks associated with the hazards, and the formation of attitudes toward these hazards. Our findings supported this assertion by demonstrating the positive effects of prior trust and communication on risk perception and acceptance of the water.

Furthermore, the finding that prior trust in the authorities (as measured in Wave 1) predicted the current levels of trust is also in line with a growing body of research conducted within the framework of the salient value similarity (SVS) approach (Cvetkovich, 1999; Siegrist, Cvetkovich, \& Roth, 2000). According to SVS, trust is based on the perceived similarity between one's own and the institution's values, as opposed to being continuously estimated based on the institution's ongoing performance, and as such it tends to persevere even in the face of negative information or events (Cvetkovich et al., 2002). A limitation of the current research is the lack of formal measures of the trust levels prior to the incident, which does not allow us to determine whether and how much trust levels decreased as a result of the incident. It appears that the pre-contamination levels of trust may have been lowered somewhat at least for those respondents who attributed blame on the municipal authorities and/or experienced sickness. Nevertheless, the overall positive ratings of trust obtained 5 and 13 months after the incident (first and second survey waves) indicate that the public at Lilla Edet held a 
continuously favorable view of their water supply institutions, pointing toward the operation of trust perseverance mechanisms.

The public's positive appraisal of the information released by the authorities and its positive effect on trust are also in line with a long-standing finding in the literature that information released by trusted institutions tends to be considered trustworthy (Earle \& Cvetkovich, 1995; Luhmann, 1979; Siegrist \& Cvetkovich, 2000). Thus, both the presumably high levels of prior trust and clear and swift communication practices appear to have contributed to the perseverance of trust in the Lilla Edet water institutions. Therefore, it may be argued that an effective course of action for water supply institutions to deal with the negative social consequences of a water contamination event is to release high-quality information swiftly, provided they have public's trust on their side. Alongside previous findings (e.g., White \& Eiser, 2005), the current research provided evidence that trusted institutions have the capacity to reduce risk perception and increase acceptance by engaging in a clear and prompt communication with the public.

As discussed before, the present study is limited by the absence of pre-event measures of key variables. An additional limitation is that some of the constructs relied on presumably less robust single-item (vs. composite) indicators. Hence, our conclusions have to remain cautious. Nonetheless, the findings presented here are consistent with a causal chain explanation of the relationships between trust, risk perception, and acceptance in the context of a contamination event. Together with Eiser et al. (2002) and Poortinga and Pidgeon's (2005) studies, it would appear that the relationship between these constructs varies as a function of the context and that there is no single and consistent causal relationship between them.

\section{Acknowledgment}

The authors would like to thank Annika Ekvall for her assistance during the running of the surveys.

\section{References}

Ajzen, I. (1985). From intentions to actions: A theory of planned behaviour. In J. Kuhl \& J. Beckmann (Eds.), Action control: From cognition to behaviour (pp. 11-39). Heidelberg, Germany: Springer.

Alhakami, A. S., \& Slovic, P. (1994). A psychological study of the inverse relationship between perceived risk and perceived benefit. Risk Analysis, 14, 1085-1096.

Bernstein, I. L. (1999). Taste aversion learning: A contemporary perspective. Nutrition, 15, 229-234.

Bord, R. J., \& O'Connor, R. E. (1992). Determinants of risk perceptions of a hazardous waste site. Risk Analysis, 12, 411-416.

Breakwell, G. (2007). The psychology of risk. Cambridge, UK: Cambridge University Press.

Burns, W. J., Slovic, P., Kasperson, R. E., Kasperson, J. X., Renn, O., \& Emani, S. (1993). Incorporating structural models into research on the social amplification of risk: Implications for theory construction and decision making. Risk Analysis, 13, 611-623.

Cvetkovich, G. (1999). The attribution of social trust. In G. Cvetkovich \& R. Löfstedt (Eds.), Social trust and the management of risk (pp. 53-61). London: Earthscan.
Cvetkovich, G., \& Löfstedt, R. (Eds.). (1999). Social trust and the management of risk. London: Earthscan.

Cvetkovich, G., Siegrist, M., Murray, R., \& Tragesser, S. (2002). New information and social trust: Asymmetry and perseverance of attributions about hazard managers. Risk Analysis, 22, 359-367.

Dunlap, R. E., Kraft, M. E., \& Rosa, E. A. (Eds.). (1993). Public reactions to nuclear waste: Citizens' views of repository siting. Durham, NC: Duke University Press.

Earle, T. C., \& Cvetkovich, G. T. (1995). Social trust: Toward a cosmopolitan society. Westport, CT: Praeger Publishers.

Echterhoff, G., Higgins, E. T., \& Levine, J. M. (2009). Shared reality: Experiencing commonality with others' inner states about the world. Perspectives on Psychological Science, 4, 496-521.

Eiser, J. R., Miles, S., \& Frewer, L. J. (2002). Trust, perceived risk and attitudes towards food technologies. Journal of Applied Social Psychology, 32, 2423 2433.

Eiser, J. R., Spears, R., \& Webley, P. (1989). Nuclear attitudes before and after Chernobyl: Change and judgement. Journal of Applied Social Psychology, 19, 689-700.

Ekvall, A. (2010). Utbrott av calicivirus i Lilla Edet-händelseförlopp och lärdomar. (in Swedish). Stockholm, Sweden: Svenskt Vatten. Retrieved July 5,
2011, from http://vav.griffel.net/filer/ Rapport_2010-13.pdf

Finucane, M. L., Alhakami, A., Slovic, P., \& Johnson, S. M. (2000). The affect heuristic in judgments of risks and benefits. Journal of Behavioral Decision Making, 13, 1-17.

Frewer, L. J. (1999). Risk perception, social trust, and public participation into strategic decision making: Implications for emerging technologies. Ambio, 28, 569-574. Retrieved July 5, 2011, from http://www.jstor.org/stable/4314956

Frewer, L. J., Howard, C., \& Shepherd, R. (1998). The influence of initial attitudes on responses to communication about genetic engineering in food production. Agriculture and Human Values, 15, 1530.

Hardin, C., \& Higgins, E. T. (1996). Shared reality: How social verification makes the subjective objective. In R. M. Sorrentino \& E. T. Higgins (Eds.), Handbook of motivation and cognition: Foundations of social behaviour (pp. 28-84). New York: Guilford Press.

Heinicke, G., Åström, J., Hartlid, C., Petterson, S., Bergstedt, O., \& Ekvall, A. (2010). Application of a QMRA model for surface water treatment to investigate a waterborne outbreak of calicivirus. American Water Works Association, Global Conference on Microbial Contaminants in 
Drinking Water 2009, 5-8 October, Singapore.s. 7.

Hurlimann, A., Hemphill, E., McKay, J., \& Geursen, G. (2008). Establishing components of community satisfaction with recycled water use through a structural equation model. Journal of Environmental Management, 88, 1221-1232.

Jorgensen, B., Graymore, M., \& O’Toole, K. (2009). Household water use behaviour: An integrated model. Journal of Environmental Management, 91, 227-236.

Kasperson, J. X., Kasperson, R. E., Pidgeon, N. F., \& Slovic, P. (2003). The social amplification of risk: Assessing fifteen years of research and theory. In $\mathrm{N}$. Pidgeon, R. E. Kasperson, \& P. Slovic (Eds.), The social amplification of risk (pp. 13-46). Cambridge, UK: Cambridge University Press.

Kelay, T., \& Fife-Schaw, C. R. (2011). Effective risk communication: A guide to best practice (THECHNEAU publication). Retrieved July 5, 2011, from http://www.techneau.org/fileadmin/files/ Publications/Publications/Deliverables/ D6.3.1-2.report.pdf

Loewenstein, G. F., Weber, E. U., Hsee, C. K., \& Welch, N. (2001). Risk as feelings. Psychological Bulletin, 127, 267-286.

Luhmann, N. (1979). Trust and power. Chichester, UK: Wiley.
Miles, S., \& Frewer, L. J. (2000). The impact of information content and presentational context on perceptions of specific food risks (Technical Annex final report to the UK Ministry of Agriculture, Fisheries, and Food). London, UK: Food Standards Agency.

Po, M., Nancarrow, B. E., Leviston, Z., Porter, N., Syme, G., \& Kaercher, J. (2005). Predicting community behaviour in relation to wastewater reuse: What drives decisions to accept or reject? Melbourne: CSIRO. Retrieved July 5, 2011, from http://www.clw.csiro.au/ publications/consultancy/2005/WfHC _Predicting_Reuse_Behaviour.pdf

Poortinga, W., \& Pidgeon, N. F. (2005). Trust in risk regulation: Cause or consequence of the acceptability of GM food? Risk Analysis, 25, 199-209.

Renn, O. (2008). Risk governance: Coping with uncertainty in a complex world. London: Earthscan.

Rundmo, T. (2002). Associations between affect and risk perception. Journal of Risk Research, 5, 119-135.

Siegrist, M., Cvetkovich, G., \& Roth, C. (2000). Salient value similarity, social trust, and risk/benefit perception. Risk Analysis, 20, 353-362.

Siegrist, M., \& Cvetkovich, G. T. (2000). Perception of hazards: The role of social trust and knowledge. Risk Analysis, 20, 713-719.

Siegrist, M., Earle, T. C., \& Gutscher, H. (2003). Test of a trust and confidence model in the applied context of electromagnetic field (EMF) risks. Risk Analysis, 23, 705-716.

Slovic, P. (1993). Perceived risk, trust, and democracy. Risk Analysis, 13, 675682.

Slovic, P. (1997). Trust, emotion, sex, politics, and science. In M. H. Bazerman, D. M. Messick, A. E. Tenbrunsel, \& K. A. Wade-Benzoni (Eds.), Environment, ethics, and behavior (pp. 277-313). San Francisco, CA: The New Lexington Press.

Slovic, P., Finucane, M. L., Peters, E., \& MacGregor, D. (2004). Risk as analysis and risk as feelings: Some thoughts about affect, reason, risk, and rationality. Risk Analysis, 24, 311-322.

White, M. P., \& Eiser, J. R. (2005). Information specificity and hazard risk potential as moderators of trust asymmetry. Risk Analysis, 25, 1187-1198.

White, M. P., Pahl, S., Buehner, M. J., \& Haye, A. (2003). Trust in risky messages: The role of prior attitudes. Risk Analysis, 23, 717-726.

Zajonc, R. B. (1980). Feeling and thinking: Preferences need no inferences. American Psychologist, 35, 151-175. 